\title{
Communication
}

\section{Improving Photocatalysis for the Reduction of CO through non-Covalent Supramolecular Assembly}

Po Ling Cheung, Savannah C. Kapper, Tian Zeng, Mark E. Thompson, and Clifford P. Kubiak

J. Am. Chem. Soc., Just Accepted Manuscript • Publication Date (Web): 06 Sep 2019

Downloaded from pubs.acs.org on September 6, 2019

\section{Just Accepted}

"Just Accepted" manuscripts have been peer-reviewed and accepted for publication. They are posted online prior to technical editing, formatting for publication and author proofing. The American Chemical Society provides "Just Accepted" as a service to the research community to expedite the dissemination of scientific material as soon as possible after acceptance. "Just Accepted" manuscripts appear in full in PDF format accompanied by an HTML abstract. "Just Accepted" manuscripts have been fully peer reviewed, but should not be considered the official version of record. They are citable by the Digital Object Identifier (DOI®). "Just Accepted" is an optional service offered to authors. Therefore, the "Just Accepted" Web site may not include all articles that will be published in the journal. After a manuscript is technically edited and formatted, it will be removed from the "Just Accepted" Web site and published as an ASAP article. Note that technical editing may introduce minor changes to the manuscript text and/or graphics which could affect content, and all legal disclaimers and ethical guidelines that apply to the journal pertain. ACS cannot be held responsible for errors or consequences arising from the use of information contained in these "Just Accepted" manuscripts. 


\title{
Improving Photocatalysis for the Reduction of $\mathrm{CO}_{2}$ Through Non- Covalent Supramolecular Assembly
}

\author{
Po Ling Cheung ${ }^{\dagger}$, Savannah C. Kapper ${ }^{\ddagger}$, Tian Zeng ${ }^{\dagger}$, Mark E. Thompson ${ }^{\ddagger}$, Clifford P. Kubiak ${ }^{\dagger *}$ \\ ${ }^{\dagger}$ Department of Chemistry and Biochemistry, University of California, San Diego, 9500 Gilman Drive, La Jolla, California \\ 92093-0358, United States \\ ${ }^{\ddagger}$ Department of Chemistry, University of Southern California, Los Angeles, California 90089, United States
}

\section{Supporting Information Placeholder}

\begin{abstract}
We report the enhancement of photocatalytic performance by introduction of hydrogen bonding interactions to a Re bipyridine catalyst and Ru photosensitizer system (ReDAC/RuDAC) by the addition of amide substituents, with carbon monoxide (CO) and carbonate/bicarbonate as products. This system demonstrates a more-than-threefold increase in turnover number (TON $\mathrm{CO}$ $=100 \pm 4)$ and quantum yield $\left(\Phi_{\mathrm{CO}}=23.3 \pm 0.8 \%\right)$ for $\mathrm{CO}$ formation compared to the control system using unsubstituted Ru photosensitizer (RuBPY) and ReDAC (TONCO $=28 \pm 4$ and $\Phi_{\mathrm{CO}}=7 \pm$ $1 \%)$ in acetonitrile (MeCN) with 1,3-dimethyl-2-phenyl-2,3-dihydro-1H-benzo[d]imidazole (BIH) as sacrificial reductant. In dimethylformamide (DMF), a solvent that disrupts hydrogen bonds, the ReDAC/RuDAC system showed a decrease in catalytic performance while the control system exhibited an increase, indicating the role of hydrogen bonding in enhancing the photocatalysis for $\mathrm{CO}_{2}$ reduction through supramolecular assembly. The similar properties of RuDAC and RuBPY demonstrated in lifetime measurements, spectroscopic analysis, electrochemical and spectroelectrochemical studies revealed that the enhancement in photocatalysis is not due to differences in intrinsic properties of the catalyst or photosensitizer, but to hydrogen bonding interactions between them.
\end{abstract}

The efficient storage of solar energy into liquid fuels is a major challenge of renewable energy today. To mimic natural photosynthesis, photocatalytic reduction of $\mathrm{CO}_{2}$ has been extensively investigated using transition metal complexes that can act as redox photosensitizers (PS) by transferring electrons upon photon excitation and as catalysts (Cat) by accepting electrons and reducing $\mathrm{CO}_{2}$. $\mathrm{Re}$ bipyridine catalysts have been shown to be excellent electrocatalysts $^{1-3}$ and photocatalysts ${ }^{4,5}$ when coupled with photosensitizers. Since 2005, the Ishitani group has studied extensively supramolecular photocatalysts by linking different photosensitizers and Re catalysts using short, covalent bridging ligands ${ }^{6-14}$. The catalytic performance of these systems is greatly improved compared to the separated systems due to the acceleration and higher yield of intramolecular electron transfer between the two components, with the rate of electron transfer as fast as $\mathrm{k}_{\mathrm{ET}}=(1.4 \pm 0.1) \times 10^{9} \mathrm{~s}^{-17}$. Recently, our laboratory estimated that the rates of electron transfer (KET) between $\mathrm{Ru}_{3} \mathrm{O}$ clusters linked by hydrogen bonded pyrimidinones were on the order of $10^{11} \mathrm{~s}^{-1} 15$. There are several reports of the influence of second coordination sphere effects, such as hydrogen bonding interactions, on catalysis ${ }^{16-19}$. Consequently, in this work, we investigate a bimolecular system, in which the photosensitizer and the catalyst form hydrogen bonding pairs, to determine the effects of non-covalent interactions on photocatalytic performance.

The system composed of $\mathrm{Ru}(\mathrm{dac})(\mathrm{bpy})_{2}\left(\mathrm{PF}_{6}\right)_{2}$ (RuDAC) $\left(4,4^{\prime}\right.$ bis(methyl acetamidomethyl)-2,2'-bipyridine = dac, 2,2'-bipyridine $=$ bpy) as the photosensitizer and $\operatorname{Re}(\mathrm{dac})(\mathrm{CO})_{3} \mathrm{Cl}(\operatorname{ReDAC})$ as the catalyst was chosen for this study (Figure 1). A previous electrochemical study of ReDAC indicated the formation of a hydrogen-bonded $\mathrm{Re}-\mathrm{Re}$ dimer in acetonitrile $(\mathrm{MeCN})^{20}$. In order to fairly assess the effects of hydrogen bonding interactions on photocatalysis, a control system composed of $\mathrm{Ru}(\mathrm{bpy})_{3}\left(\mathrm{PF}_{6}\right)_{2}(\mathrm{RuBPY})$ and ReDAC was used for comparison (Figure 1). RuBPY has similar reduction potentials, UV-vis absorption spectrum, and excited state lifetime as RuDAC.

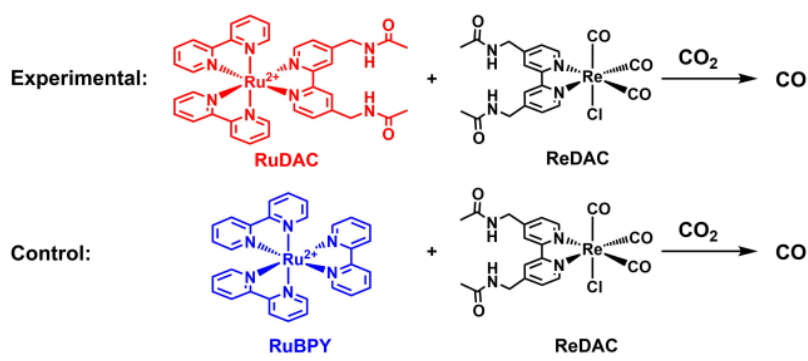

Scheme 1. Experimental and control systems for investigation of hydrogen bonding effects on photocatalysis.

$\mathrm{ReDAC}^{20}$ and $\mathrm{BIH}^{21}$ were synthesized as reported and RuDAC was synthesized by adapting methods in the literature ${ }^{22}$. In a typical mixed system with the Ru photosensitizer and catalyst as separate components, the $\mathrm{Ru}$ photosensitizer $\left(\mathrm{Ru}^{2+}\right)$ is first excited by light and then reduced by a sacrificial reductant (D), followed by electron transfer from the singly reduced $\mathrm{Ru}$ photosensitizer $\left(\mathrm{Ru}^{*+}\right)$ to the catalyst ${ }^{23,24}$ (Scheme 2). The latter step (eq. 2 in Scheme 2) is driven by the difference between the redox potential of $\mathrm{Ru}^{\circ+}$ and catalyst. To better demonstrate the impact of hydrogen bonding on photocatalysis, the first reduction potential of the photosensitizer should be comparable to that of the catalyst so that there is a low driving force for electron transfer. In the previous study, ReDAC was reported to display its first reduction at $-1.77 \mathrm{~V}\left(\mathrm{vs} . \mathrm{Fc}^{+/ 0}\right)^{20}$. Cyclic voltammograms (CVs) of RuDAC, RuBPY and $\mathrm{Ru}(\mathrm{dmb})_{3}\left(\mathrm{PF}_{6}\right)_{2}(\mathrm{RuDMB}$, where 4,4'-dimethyl-2,2'-bipyridine $=$ $\mathrm{dmb}$ ) were taken under Ar in dry $\mathrm{MeCN}$ solutions containing 0.1 $\mathrm{M}$ tetrabutylammonium hexafluorophosphate $\left(\mathrm{TBAPF}_{6}\right)$. Within experimental error, the CVs of RuDAC and RuBPY display first 
reduction potentials at $-1.76 \mathrm{~V}$, making them excellent trial systems comparing hydrogen bonding effects in this study. Another commonly used photosensitizer, RuDMB, has a more negative reduction potential at $-1.88 \mathrm{~V}$. The increased driving force for electron transfer could mask hydrogen bonding effects. Therefore, RuBPY was chosen to be the control for comparison of catalytic performance without a hydrogen bonding interaction.

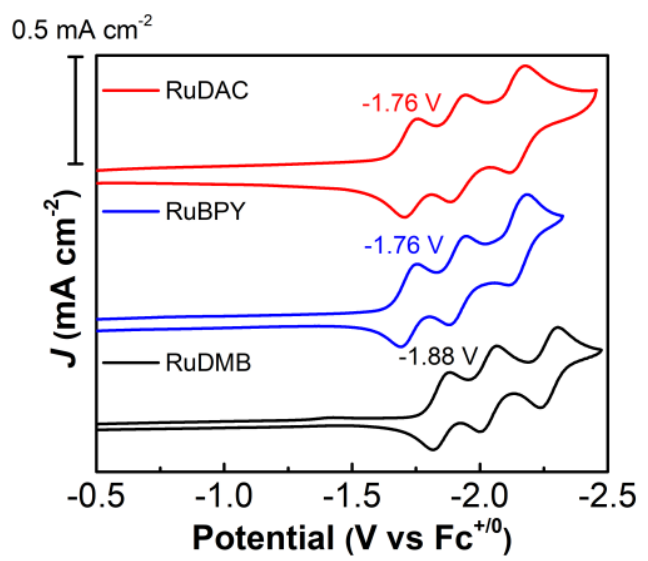

Figure 1. Cyclic voltammograms of $1 \mathrm{mM}$ of RuDAC (red), RuBPY (blue) and RuDMB (black) in dry MeCN containing 0.1 $\mathrm{M} \mathrm{TBAPF}_{6}$ at scan rate $100 \mathrm{mV} / \mathrm{s}$ under Ar.

$$
\begin{aligned}
& \mathrm{Ru}^{2+*}+\mathrm{D} \longrightarrow \mathrm{Ru}^{++}+\mathrm{D}^{+} \\
& \mathrm{Ru}^{++}+\mathrm{Cat} \longrightarrow \mathrm{Cat}^{-}+\mathrm{Ru}^{2+}
\end{aligned}
$$

Scheme 2. A simplified scheme showing reductive quenching of the $\mathrm{Ru}$ photosensitizer $(\mathrm{Ru})$ by sacrificial reductant $(\mathrm{D})$ and then the electron transfer from singly reduced $\mathrm{Ru}$ to the catalyst (Cat).

A series of photocatalytic studies were performed by irradiating solutions that were $0.5 \mathrm{mM}$ in photosensitizer, $0.5 \mathrm{mM}$ in catalyst, $0.1 \mathrm{M}$ in 1,3-dimethyl-2-phenyl-2,3-dihydro-1H-benzo[d]imidazole $(\mathrm{BIH})$ in dry $\mathrm{MeCN}$ or $N, N$-dimethylformamide (DMF) under $\mathrm{CO}_{2}$ or $\mathrm{Ar}$ at $470 \mathrm{~nm}$ for $4 \mathrm{~h}$. The common practice of using triethanolamine (TEOA) as proton source and 1-benzyl-1,4-dihydronicotinamide (BNAH) as sacrificial reductant was not adopted in this study as these have hydroxyl or amide groups which are capable of interrupting the hydrogen bonding between the photosensitizer and the catalyst. The systems in this study work surprisingly well without the added proton source, and it is likely due to the disproportionation mechanism of $2 \mathrm{CO}_{2}+2 \mathrm{e}^{-}$to $\mathrm{CO}$ and $\mathrm{CO}_{3}{ }^{2-}$ or $\mathrm{HCO}_{3}{ }^{-}$ $\left([\mathrm{H}] \mathrm{CO}_{3}{ }^{[2]-}\right)$ by the ReDAC catalyst ${ }^{20}$. In MeCN solutions, hydrogen bonds can be formed between amide substituents as demonstrated in previous electrochemical studies of ReDAC ${ }^{20}$. The photocatalytic reactions were run for 4 hours only because over half of the $\mathrm{BIH}$ was consumed. After 4 hours of irradiation, the RuDAC/ReDAC system exhibits a more-than-threefold increase in photocatalytic reduction of $\mathrm{CO}_{2}$ with a higher turnover number $\left(\mathrm{TON}_{\mathrm{CO}}=100 \pm 4\right)$ and quantum yield $\left(\Phi_{\mathrm{CO}}=23.3 \pm 0.8 \%\right)$ for $\mathrm{CO}$ production compared to the RuBPY/ReDAC control system $\left(\mathrm{TON}_{\mathrm{CO}}=28 \pm 4\right.$ and $\left.\Phi_{\mathrm{CO}}=7 \pm 1 \%\right)$ as shown in Figure 2. To further test hydrogen bonding as the principal cause for these observations, similar photocatalytic studies were done in DMF, a solvent that interrupts hydrogen bond formation. In DMF (Figure 2), the RuBPY/ReDAC control system displays improvement in catalysis $\left(\mathrm{TON}_{\mathrm{CO}}=43 \pm 9\right.$ and $\left.\Phi_{\mathrm{CO}}=11 \pm 1 \%\right)$ while the $\mathrm{RuDAC} / \mathrm{Re}-$ DAC system displays a decrease in catalysis $\left(\mathrm{TON}_{\mathrm{CO}}=79 \pm 8\right.$ and $\Phi_{\mathrm{CO}}=18 \pm 1 \%$ ), but it still outperforms the RuBPY/ReDAC system. Thus, the two systems exhibit opposite responses to different solvents. The higher activity of the RuDAC/ReDAC system compared to the control system in DMF is unexpected, but it is likely due to increased contact surface area between photosensitizer and catalyst $^{25}$. The reason for higher activity of RuBPY/ReDAC in DMF compared to MeCN remains unclear, but previous studies show that solvents play important roles in controlling catalytic rates and selectivity ${ }^{23,26-30}$. Since the RuDAC/ReDAC system behaves in a trend opposite to the control, it is reasonable to conclude that hydrogen bonding is the dominant factor influencing differences in performance.

In addition to gaseous products, the liquid mixtures were analyzed. No formate is detected with ${ }^{1} \mathrm{H}$ NMR (Table S1 and S2) but appreciable $[\mathrm{H}] \mathrm{CO}_{3}{ }^{[2]-}$ are observed with IR. It is known that $\mathrm{Re}-$ DAC undergoes the disproportionation mechanism of $2 \mathrm{CO}_{2}+2 \mathrm{e}$ $\leftrightharpoons \mathrm{CO}$ and $\mathrm{CO}_{3}{ }^{2-}$ in electrocatalysis ${ }^{20}$. When a proton source is not used in the photocatalytic experiments, bands are observed in the IR at 1672 and $1637 \mathrm{~cm}^{-1}$, consistent with formation of $[\mathrm{H}] \mathrm{CO}_{3}{ }^{[2]-}$ species (Figure S5). Repeating these experiments with ${ }^{13} \mathrm{CO}_{2}$ showed shifts in these bands ( 1625 and $\left.1598 \mathrm{~cm}^{-1}\right)$, consistent with isotopic labeling ${ }^{20,31}$. Control studies under Ar reveal no $\mathrm{CO}$ or $\mathrm{H}_{2}$ production upon irradiation (Table $\mathrm{S} 2$ ). In addition, control reactions without ReDAC reveal that RuDAC is a better catalyst than $\mathrm{RuBPY}$ in both solvents and it performed better in MeCN than in DMF. These observations are similar to the trend seen in the Ru$\mathrm{DAC} / \mathrm{ReDAC}$ system, but the absence of the Re catalyst significantly slows down the rate of CO formation (Table S2).

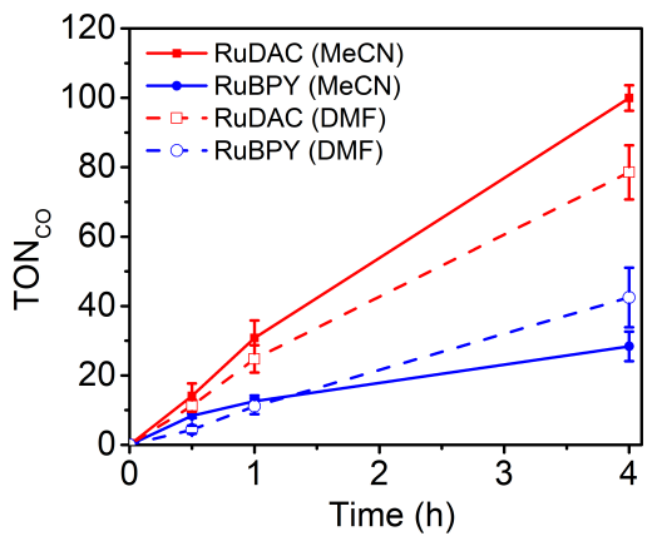

Figure 2. Turnover number of $\mathrm{CO}\left(\mathrm{TON}_{\mathrm{CO}}\right)$ produced by Ru$\mathrm{DAC} / \mathrm{ReDAC}$ (red) and RuBPY/ReDAC (blue) in MeCN (solid line) and DMF (dotted line) solvents.

Several additional experiments were carried out to understand the origin of the enhancement in photocatalytic activity in the $\mathrm{Ru}-$ DAC/ReDAC system compared to RuBPY/ReDAC. Further support for hydrogen bonding interactions was gained as contributions arising from discrepancies in light absorption by the photosensitizers, faster electron transfer from $\mathrm{BIH}$ to the photosensitizer, and other interactions of the photosensitizer with the catalyst were ruled out. First, the photochemical properties of the photosensitizers were investigated. The UV-visible absorption measurements of the three photosensitizers show comparable molar absorptivity at 470 $\mathrm{nm}$, which is the wavelength used for photocatalysis (Table 1 and Figure S3). The lifetimes of the excited states were measured by Time-Correlated Single Photon Counting (TCSPC) with excitation wavelength at $405 \mathrm{~nm}$ at room temperature. The lifetimes of excited RuDAC were found to be $980 \mathrm{~ns}$ and $910 \mathrm{~ns}$ in $\mathrm{MeCN}$ and DMF respectively (Table 1 and Fig. S6). Since there is a range of values for the reported lifetimes of RuBPY ${ }^{32}$ and $\mathrm{RuDMB}^{13,33}$, we measured them in this work for consistency (Table 1). The photoinduced 
Table 1. Photochemical properties of RuDAC, RuBPY and RuDMB.

\begin{tabular}{ccccccc} 
complex & $\lambda_{\mathrm{em}(\mathrm{MeCN})}(\mathrm{nm})^{a}$ & $\lambda_{\mathrm{em}(\mathrm{DMF})}(\mathrm{nm})^{a}$ & $\varepsilon_{470}\left(\mathrm{~L} \mathrm{~mol}^{-1} \mathrm{~cm}^{-1}\right)$ & $\tau_{\mathrm{MeCN}}(\mathrm{ns})^{b}$ & $\tau_{\mathrm{DMF}}(\mathrm{ns})^{b}$ & $\kappa_{q(\mathrm{MeCN})}\left(\mathrm{M}^{-1} \mathrm{~s}^{-1}\right)^{c}$ \\
RuDAC & 613 & 620 & 7200 & 980 & 910 & $5.9 \pm 0.2 \times 10^{9}$ \\
RuBPY & 609 & 618 & 9000 & 930 & 930 & $7.2 \pm 0.2 \times 10^{9}$ \\
RuDMB & 618 & 624 & 8100 & 900 & 790 & $2.6 \pm 0.2 \times 10^{9}$ \\
\hline
\end{tabular}

${ }^{a}$ A dry MeCN or DMF solution containing the Ru complex was measured using fluorometer. ${ }^{b}$ The fluorescence lifetimes were measured in dry MeCN or DMF using TCSPC with excitation wavelength at $405 \mathrm{~nm}$ at room temperature ${ }^{c}$ The quenching constants were obtained by the Stern-Volmer plot of reductive quenching with BIH in dry MeCN or DMF (Fig. S7 and S8)

electron transfer from BIH to Ru photosensitizers is the initial process in the photocatalytic $\mathrm{CO}_{2}$ reduction ${ }^{34}$. To determine the rate of this process, the quenching constant $\left(k_{\mathrm{q}}\right)$ was found by fluorescence lifetime measurements and the following equation ${ }^{35}$ :

$$
\frac{\tau_{0}}{\tau}=1+\tau_{0} \kappa_{q}[Q]=1+K_{D}[\mathrm{Q}]
$$

Here, $\tau_{0}$ and $\tau$ are the fluorescence lifetimes without and with the quencher respectively, $k_{\mathrm{q}}$ is the biomolecular quenching constant, $\mathrm{K}_{\mathrm{D}}$ is the Stern-Volmer constant for dynamic quenching, and $\mathrm{Q}$ is the quencher. By plotting the Stern-Volmer relationship (Fig. S7 and S8), the slope was used to calculate the quenching rate constant $\left(k_{\mathrm{q}}\right)$ using eq. 1 . The non-zero slope from the plots suggests dynamic quenching between BIH and the Ru photosensitizers. While the quenching rates of RuDAC and RuBPY are comparable to each other in $\mathrm{MeCN}$ and DMF respectively, the rates in $\mathrm{MeCN}$ are two to three times higher than those in DMF, indicating a faster electron transfer process in $\mathrm{MeCN}$ (Table 1).

Further electrochemical studies were carried out to examine the interaction between photosensitizer and catalyst. RuDAC has three quasi-reversible reduction peaks at $-1.76 \mathrm{~V},-1.52 \mathrm{~V}$ and $-2.18 \mathrm{~V}$ in MeCN and DMF (Figure S11 and S12) respectively. Similar to other Ru bipyridine complexes ${ }^{36}$, RuDAC itself exhibits current enhancement under a $\mathrm{CO}_{2}$ atmosphere in both solvent systems (Figure S9 and S10). Addition of ReDAC to the cell causes no significant changes to the three reversible reductions of RuDAC. However, as revealed in the $\mathrm{CV}$ of $\mathrm{RuDAC} / \mathrm{ReDAC}$ in $\mathrm{MeCN}$ under $\mathrm{CO}_{2}$ (Figure S13), the characteristic catalytic peak at around $-1.8 \mathrm{~V}$ vs. $\mathrm{Fc}^{+/ 0}$ is similar to $\mathrm{ReDAC}$ alone in $\mathrm{MeCN}^{20}$, suggesting the formation of the ReDAC dimer. This indicates that the presence of RuDAC does not interfere in the catalytic reaction of ReDAC. The absence of the ReDAC hydrogen bonded dimer feature in the $\mathrm{CV}$ under catalytic conditions in DMF (Figure S14) also provides clear evidence that DMF disrupts hydrogen bonding ${ }^{20}$. To further test this hypothesis, IR spectroelectrochemistry (IR-SEC) studies were conducted on the RuDAC/ReDAC system in $\mathrm{MeCN}$ under $\mathrm{N}_{2}$. The IR spectra of Figure S15 indicate the formation of the Re-Re dimer from ReDAC as reported in a previous electrochemical study ${ }^{20}$, indicating that RuDAC is unlikely to affect the catalytic mechanism of ReDAC. Using NMR concentration studies, we estimate the association constant $\left(\mathrm{K}_{\mathrm{a}}\right)$ for the hetero-dimer of [ReDAC $\left.\cdots \mathrm{RuDAC}\right]$ to be approximately $300 \mathrm{M}^{-1}$ in MeCN (Figure S16) ${ }^{37}$, which is close to the self-dimerization constant of ReDAC ${ }^{20}$. Although an approximately statistical mixture of homo- and hetero-dimers is expected in the RuDAC/ReDAC system, the hydrogen bonding interaction is strong enough to boost catalysis significantly.

In conclusion, the findings reported here taken together demonstrate that appending amide groups to photosensitizer and catalyst significantly improves photocatalysis in $\mathrm{MeCN}$ by enabling hydrogen bonding interactions. To the best of our knowledge, this constitutes the first report of successfully utilizing hydrogen bonding groups on photosensitizers and catalysts to improve photocatalytic $\mathrm{CO}_{2}$ reduction. A forthcoming study will employ specific hydrogen bond donor and acceptors on photosensitizers and catalysts to eliminate self-dimerization effects.

\section{ASSOCIATED CONTENT}

\section{Supporting Information}

The Supporting Information is available free of charge on the ACS Publications

website.

Experimental details and additional NMR, mass spectrum, TCSPC traces, Stern-Volmer plots, UV-vis spectrum, infrared, electrochemical and photochemical studies and IR-SEC.

\section{AUTHOR INFORMATION}

\section{Corresponding Author}

*ckubiak@ucsd.edu

\section{ORCID}

Po Ling Cheung: 0000-0002-2717-0339

Mark E. Thompson: 0000-0002-7764-4096

Clifford P. Kubiak: 0000-0003-2186-488X

\section{Present Addresses}

$\perp$ Division of Chemistry and Chemical Engineering, California Institute of Technology, Pasadena, California 91125, United States

\section{Notes}

The authors declare no competing financial interests.

\section{ACKNOWLEDGMENT}

This project was supported by two funding sources. A grant from the Air Force Office of Scientific Research (AFOSR), Basic Research Initiative (BRI) grant (FA9550-12-1-0414), supported Cheung, Zeng, and Kubiak, whose work involved synthesis and characterization of all compounds, photocatalytic studies, electrochemical studies, IR-SEC studies, NMR studies, fluorescence measurements and data analysis. The Office of Basic Energy Sciences at the Department of Energy (DE-SC0016450) supported Kapper and Thompson, whose work involved TCSPC measurements, fluorescence measurements, and data analysis.

\section{REFERENCES}

1. Clark, M. L.; Cheung, P. L.; Lessio, M.; Carter, E. A.; Kubiak, C. P., Kinetic and Mechanistic Effects of Bipyridine (bpy) Substituent, Labile Ligand, and Brønsted Acid on Electrocatalytic $\mathrm{CO}_{2}$ Reduction by Re(bpy) Complexes. ACS Catal. 2018, 8 (3), 2021-2029.

2. Hawecker, J.; Lehn, J. M.; Ziessel, R., Electrocatalytic reduction of carbon dioxide mediated by $\mathrm{Re}($ bipy $)(\mathrm{CO})_{3} \mathrm{Cl}$ (bipy $=2,2^{\prime} \quad$-bipyridine). $J$. Chem. Soc., Chem. Commun. 1984, 328-330.

3. Hawecker, J.; Lehn, J. M.; Ziessel, R., Photochemical and Electrochemical Reduction of Carbon Dioxide to Carbon Monoxide Mediated by (2,2' - Bipyridine)tricarbonylchlororhenium(I) and Related Complexes as Homogeneous Catalysts. Helv. Chim. Acta 1990, 69, 19902013. 
4. Koike, K.; Hori, H.; Ishizuka, M.; Westwell, J. R.; Takeuchi, K.; Ibusuki, T.; Enjouji, K.; Konno, H.; Sakamoto, K.; Ishitani, O., Key Process of the Photocatalytic Reduction of $\mathrm{CO}_{2}$ Using [ $\mathrm{Re}\left(4,4^{4}-\mathrm{X}_{2-}\right.$ bipyridine $\left.)(\mathrm{CO})_{3} \mathrm{PR}_{3}\right]+\left(\mathrm{X}=\mathrm{CH}_{3}, \mathrm{H}, \mathrm{CF}_{3} ; \mathrm{PR}_{3}=\right.$ Phosphorus Ligands $)$ : Dark Reaction of the One-Electron-Reduced Complexes with $\mathrm{CO}_{2}$. Organometallics 1997, 16, 5724-5729.

5. Agarwal, J.; Fujita, E.; Schaefer, H. F.; Muckerman, J. T., Mechanisms for $\mathrm{CO}$ Production from $\mathrm{CO}_{2}$ Using Reduced Rhenium Tricarbonyl Catalysts. J. Am. Chem. Soc. 2012, 134, 5180-5186.

6. Kamata, R.; Kumagai, H.; Yamazaki, Y.; Sahara, G.; Ishitani, O., Photoelectrochemical $\mathrm{CO}_{2}$ Reduction Using a $\mathrm{Ru}(\mathrm{II})-\mathrm{Re}(\mathrm{I})$

Supramolecular Photocatalyst Connected to a Vinyl Polymer on a NiO Electrode. ACS Appl. Mater. Interfaces 2019, 11 (6), 5632-5641.

7. Koike, K.; Grills, D. C.; Tamaki, Y.; Fujita, E.; Okubo, K.; Yamazaki, Y.; Saigo, M.; Mukuta, T.; Onda, K.; Ishitani, O., Investigation of excited state, reductive quenching, and intramolecular electron transfer of $\mathrm{Ru}(\mathrm{II})-\mathrm{Re}(\mathrm{I})$ supramolecular photocatalysts for $\mathrm{CO}_{2}$ reduction using time-resolved IR measurements. Chem. Sci. 2018, 9, 2961-2974.

8. Kumagai, H.; Sahara, G.; Maeda, K.; Higashi, M.; Abe, R.; Ishitani, O., Hybrid Photocathode Consisting of $\mathrm{CuGaO}_{2} p$-Type Semiconductor and a Ru(II)-Re(I) Supramolecular Photocatalyst: NonBiased Visible-Light-Driven $\mathrm{CO}_{2}$ Reduction with Water Oxidation. Chem. Sci. 2017, 8, 4242-4249.

9. Kuramochi, Y.; Ishitani, O., Iridium(III) 1-Phenylisoquinoline Complexes as a Photosensitizer for Photocatalytic $\mathrm{CO}_{2}$ Reduction: A Mixed System with a $\operatorname{Re}(\mathrm{I})$ Catalyst and a Supramolecular Photocatalyst. Inorg. Chem. 2016, 55, 5702-5709.

10. Sato, S.; Koike, K.; Inoue, H.; Ishitani, O., Highly efficient supramolecular photocatalysts for $\mathrm{CO}_{2}$ reduction using visible light. Photochem. Photobiol. Sci. 2007, 6 (4), 454-61.

11. Tamaki, Y.; Ishitani, O., Supramolecular Photocatalysts for the Reduction of $\mathrm{CO}_{2}$. ACS Catal. 2017, 7 (5), 3394-3409.

12. Tamaki, Y.; Koike, K.; Morimoto, T.; Yamazaki, Y.; Ishitani, O., Red-Light-Driven Photocatalytic Reduction of $\mathrm{CO}_{2}$ using Os(II)-Re(I) Supramolecular Complexes. Inorg. Chem. 2013, 52, 11902-11909. 13. Tamaki, Y.; Watanabe, K.; Koike, K.; Inoue, H.; Morimoto, T.; Ishitani, O., Development of highly efficient supramolecular $\mathrm{CO}_{2}$ reduction photocatalysts with high turnover frequency and durability. Faraday Discuss. 2012, 155, 115-127.

14. Ueda, Y.; Takeda, H.; Yui, T.; Koike, K.; Goto, Y.; Inagaki, S.; Ishitani, O., A Visible-Light Harvesting System for Efficient $\mathrm{CO}_{2}$ Reduction Using a Supramolecular Ru(II)-Re(I) Photocatalyst Adsorbed in Periodic Mesoporous Organosilica. ChemSusChem 2015, 8, 439-442. 15. Porter, T. M.; Heim, G. P.; Kubiak, C. P., Stable Mixed-Valent Complexes Formed by Electron Delocalization Across Hydrogen Bonds of Pyrimidinone-Linked Metal Clusters. J. Am. Chem. Soc. 2018, 140 (40), 12756-12759.

16. Sahu, S.; Cheung, P. L.; Machan, C. W.; Chabolla, S. A.; Kubiak, C. P.; Gianneschi, N. C., Charged Macromolecular Rhenium Bipyridine Catalysts with Tunable $\mathrm{CO}_{2}$ Reduction Potentials. Chem. Eur. J. 2017, 23, 8619-8622.

17. Azcarate, I.; Costentin, C.; Robert, M.; Savéant, J.-M., ThroughSpace Charge Interaction Substituent Effects in Molecular Catalysis Leading to the Design of the Most Efficient Catalyst of $\mathrm{CO}_{2}$-to-CO Electrochemical Conversion. J. Am. Chem. Soc. 2016, 138, 16639-16644. 18. Doud, M. D.; Grice, K. A.; Lilio, A. M.; Seu, C. S.; Kubiak, C. P., Versatile Synthesis of $\mathrm{PR}_{2} \mathrm{NR}_{2}$ Ligands for Molecular Electrocatalysts with Pendant Bases in the Second Coordination Sphere. Organometallics 2012, 31, 779-782.

19. Bays, J. T.; Priyadarshani, N.; Jeletic, M. S.; Hulley, E. B.; Miller, D. L.; Linehan, J. C.; Shaw, W. J., The Influence of the Second and Outer Coordination Spheres on $\mathrm{Rh}$ (diphosphine) ${ }_{2} \mathrm{CO}_{2}$ Hydrogenation Catalysts. ACS Catal. 2014, 4, 3663-3670.

20. Machan, C. W.; Chabolla, S. A.; Yin, J.; Gilson, M. K.; Tezcan, F. A.; Kubiak, C. P., Supramolecular assembly promotes the electrocatalytic reduction of carbon dioxide by $\operatorname{Re}(\mathrm{I})$ bipyridine catalysts at a lower overpotential. J. Am. Chem. Soc. 2014, 136 (41), 14598-607.

21. Hong, D.; Tsukakoshi, Y.; Kotani, H.; Ishizuka, T.; Kojima, T., Visible-Light-Driven Photocatalytic $\mathrm{CO}_{2}$ Reduction by a Ni(II) Complex Bearing a Bioinspired Tetradentate Ligand for Selective CO Production. $J$. Am. Chem. Soc. 2017, 139 (19), 6538-6541.

22. Aranyos, V.; Hagfeldt, A.; Grennberg, H.; Figgemeier, E., Electropolymerisable bipyridine ruthenium(II) complexes: synthesis, spectroscopic and electrochemical characterisation of 4-((2-thienyl) ethenyl)- and 4,4' -di((2-thienyl) ethenyl)-2,2' -bipyridine ruthenium complexes. Polyhedron 2004, 23 (4), 589-598.

23. Cheung, P. L.; Machan, C. W.; Malkhasian, A. Y.; Agarwal, J.; Kubiak, C. P., Photocatalytic Reduction of Carbon Dioxide to CO and $\mathrm{HCO}_{2} \mathrm{H}$ Using fac- $\mathrm{Mn}(\mathrm{CN})(\mathrm{bpy})(\mathrm{CO})_{3}$. Inorg. Chem. 2016, 55 (6), $3192-$ 8.

24. Yamazaki, Y.; Takeda, H.; Ishitani, O., Photocatalytic reduction of $\mathrm{CO}_{2}$ using metal complexes. J. Photochem. Photobiol. C: Photochem.

Rev. 2015, 25, 106-137.

25. Porter, T. M.; Canzi, G. C.; Chabolla, S. A.; Kubiak, C. P., Tuning Electron Delocalization and Transfer Rates in Mixed-Valent $\mathrm{Ru}_{3} \mathrm{O}$ Complexes through "Push-Pull" Effects. J. Phys. Chem. A 2016, 120 (32), 6309-6316

26. Takeda, H.; Kamiyama, H.; Okamoto, K.; Irimajiri, M.; Mizutani, T.; Koike, K.; Sekine, A.; Ishitani, O., Highly Efficient and Robust Photocatalytic Systems for $\mathrm{CO}_{2}$ Reduction Consisting of a $\mathrm{Cu}(\mathrm{I})$ Photosensitiser and Mn(I) Catalysts. J. Am. Chem. Soc. 2018, 140, 1724117254 .

27. Morimoto, T.; Nakajima, T.; Sawa, S.; Nakanishi, R.; Imori, D.; Ishitani, $\mathrm{O}, \mathrm{CO}_{2}$ capture by a rhenium(I) complex with the aid of triethanolamine. J. Am. Chem. Soc. 2013, 135 (45), 16825-8.

28. Paul, A.; Connolly, D.; Schulz, M.; Pryce, M. T.; Vos, J. G., Effect of Water during the Quantitation of Formate in Photocatalytic Studies on $\mathrm{CO}_{2}$ Reduction in Dimethylformamide. Inorg. Chem. 2012, 51, 19771979 .

29. Kuramochi, Y.; Kamiya, M.; Ishida, H., Photocatalytic $\mathrm{CO}_{2}$ Reduction in $N, N$-Dimethylacetamide/Water as an Alternative Solvent System. Inorg. Chem. 2014, 53, 3326-3332.

30. Lee, S. K.; Kondo, M.; Okamura, M.; Enomoto, T.; Nakamura, G.; Masaoka, S., Function-Integrated Ru Catalyst for Photochemical $\mathrm{CO}_{2}$ Reduction. J. Am. Chem. Soc. 2018, 140 (49), 16899-16903.

31. Sampson, M. D.; Kubiak, C. P., Manganese Electrocatalysts with Bulky Bipyridine Ligands: Utilizing Lewis Acids To Promote Carbon Dioxide Reduction at Low Overpotentials. J. Am. Chem. Soc. 2016, 138 (4), 1386-1393.

32. Arias-Rotondo, D. M.; McCusker, J. K., The photophysics of photoredox catalysis: a roadmap for catalyst design. Chem. Soc. Rev. 2016, 45 (21), 5803-5820.

33. Kato, E.; Takeda, H.; Koike, K.; Ohkuboa, K.; Ishitani, O., Ru(II)$\mathrm{Re}(\mathrm{I})$ binuclear photocatalysts connected by $-\mathrm{CH}_{2} \mathrm{XCH}_{2}-\left(\mathrm{X}=\mathrm{O}, \mathrm{S}, \mathrm{CH}_{2}\right)$ for $\mathrm{CO}_{2}$ reduction. Chem. Sci. 2015, 6, 3003-3012.

34. Kuramochi, Y.; Ishitani, O.; Ishida, H., Reaction mechanisms of catalytic photochemical $\mathrm{CO}_{2}$ reduction using $\mathrm{Re}(\mathrm{I})$ and $\mathrm{Ru}(\mathrm{II})$ complexes. Coord. Chem. Rev. 2018, 373, 333-356.

35. Fraiji, L. K.; Hayes, D. M.; Werner, T. C., Static and dynamic fluorescence quenching experiments for the physical chemistry laboratory. J. Chem. Educ. 1992, 69, 424-428.

36. Ishida, H.; Tanaka, K.; Tanaka, T., Electrochemical $\mathrm{CO}_{2}$ reduction catalyzed by ruthenium complexes $\left[\mathrm{Ru}(\mathrm{bpy})_{2}(\mathrm{CO})_{2}\right]^{2+}$ and $\left[\mathrm{Ru}(\mathrm{bpy})_{2}(\mathrm{CO}) \mathrm{Cl}\right]^{+}$. Effect of $\mathrm{pH}$ on the formation of $\mathrm{CO}$ and $\mathrm{HCOO}$. Organometallics 1987, 6 (1), 181-186.

37. Hynes, M. J., EQNMR: A computer program for the calculation of stability constants from nuclear magnetic resonance chemical shift data. $J$. Chem. Soc., Dalton Trans. 1993, 311-312. 
Insert Table of Contents artwork here
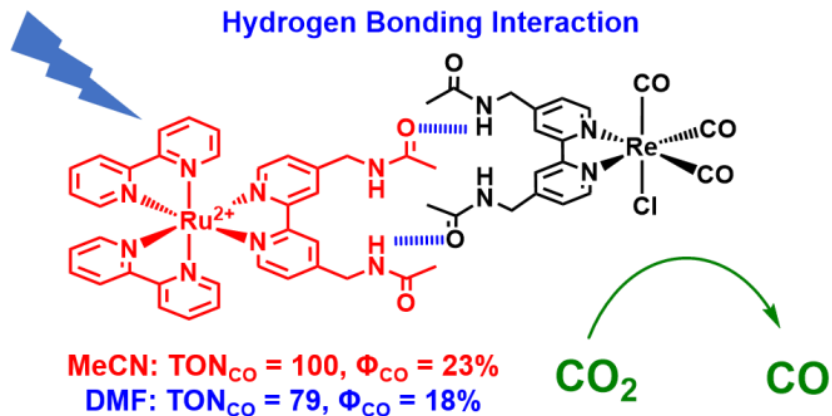
DMF: TON $_{\mathrm{CO}}=79, \Phi_{\mathrm{CO}}=18 \%$ 